\title{
ALGUMAS NOTAS SOBRE A 'CONSTITUCIONALIZAÇÃO’ DO DIREITO PRIVADO
}

\author{
Roberta Drehmer de Miranda ${ }^{1}$
}

\begin{abstract}
RESUMO: O Direito Constitucional na pós-modernidade apresenta uma nova moldura diante do fenômeno do "constitucionalismo dos valores", proveniente do fim da Segunda Guerra Mundial, a partir da inserção de princípios básicos e direitos humanos fundamentais nos textos das Constituições Estatais até então de origem e linha liberais. Esse mes mo fenômeno trou xe, igualmente, a recepção pelo Direito Constitucional de institutos próprios do direito privado, trazendo a tona a discussão acerca de uma provável "constitucionalização" (ou seja, tornar constitucional) do direito civil, elevando essa disciplina a um nível primeiro e máximo do direito. Contudo, o que efetivamente ocorre, na contemporaneidade, é a aceitação, nos textos das Constituições, de institutos os quais não tinham proteção constitucional, seja por seus fundamentos, sejam para fins de objeto de controle de constitucionalidade. Em verdade, não existe "constitucionalização" do direito privado, cuja natureza é de direito concreto, num nível próximo; existe, simplesmente, a garantia constitucional de institutos privados desprotegidos na idéia liberal de Constituição.
\end{abstract}

PAlavras-ChaVE: Constitucionalização. Direitos Fundamentais. Direito Privado. Dritwirkung.

\section{SOME NOTES ABOUT THE PRIVATE LAW 'CONSTITUTIONALIZATION’}

\begin{abstract}
The contemporary Constitutional law shows a new feature up against the "constitutionalism of values" phenomenon, comming from the end of the Second War, with the admission of basics principles and fundamental human rights in the Constitutions origin from liberal thought. This phenomenon brought the reception by the Constitutional law of peculiar institutes from civil law, as well the discussion about a probably "constitutionalization" (it means, to become constitutional) of civil law, putting on this subject to a primus and maximum standart in law. However, what really hapens, today, is the acception in the Constitutional texts of institutes wich did not have constitutional protection, due to thouse fundaments, or in order to be object of constitutional review. In fact, does not exist "constitutionalization" of the civil law, wich nature is concrect law, in a local standart; what only exist is the constitutional garantee of civil institutes desprotected by the liberal vision of Constitution.
\end{abstract}

KEY WORDS: 'Constitutionalization'. Human Rights. Private Law. Dritwirkung.

SUMÁRIO: Considerações iniciais. I) Do Constitucionalismo à construção da noção de "constitucionalização do direito privado". A) O Constitucionalismo norte-americano e europeu: breves considerações acerca da formação histórica do Estado Liberal e do Estado Social de Direito. B) O "Constitucionalismo de valores" do pós-Segunda Guerra e a "constitucionalização" de institutos de direito civil: o exemp lo alemão. II) A "constitucionalização" do direito civil na contemporaneidade. A) A relação dos direitos fundamentais constitucionais e os direitos civis: limites constitucionais ao direito privado. B) O direito privado na constituição: desafios na pós-modernidade. Considerações finais. Referências bibliográficas.

\footnotetext{
${ }^{1}$ Bacharel em Dire ito pela Universidade Federal do Rio Grande do Sul (UFRGS). Mestre em Direito Público pela Universidade Federal do Rio Grande do Sul (UFRGS). Doutoranda em Direito pela Universidade Federal do Rio Grande do Sul (UFRGS), na linha de pesquisa "Fundamentos TeóricoFilosóficos da Experiência Jurídica", com tese em Socio logia do Direito. Advogada. Bolsista do CAPES. Pesquis adora.
} 


\section{CONSIDERAÇÕES INICIAIS}

"A necessidade de interpretar o presente significa comparar o passado, como processo histórico, e também olhar para o futuro, como perspectiva de sociedade (não somente como indivíduo)"2. A afirmação do jurista argentino CARLOS ALBERTO GHERSI leva-nos à reflexão sobre de que modo observamos e analisamos um fenômeno e como o apresentamos, seja na forma de um discurso lógico, dialético, por vezes retórico, seja eminentemente científico. Quer dizer, a que finalidade nos dirigimos quando queremos expor a realidade sobre o fenômeno analisado. É o ponto de partida, pois, sobre o qual buscamos, no presente artigo, analisar o que por fim se cunha de "constitucionalização do direito privado", e de que modo dito fenômeno jurídico alcançou ênfase de estudo tanto no Direito Constitucional como no Direito Civil.

Nosso panorama, portanto, será fundamentalmente histórico-político, com algumas referências importantes à doutrina e teoria do Direito bem como algumas conclusões acerca da importância deste tema na contemporaneidade (ou "pósmodernidade" ${ }^{3}$ ), sem afastar a análise crítica acerca da forma como o assunto vem sendo trabalhado no Direito Constitucional e no Direito Privado.

\section{I - DO CONSTITUCIONALISMO À CONSTRUÇÃO DA NOÇÃO DE "CONSTITUCIONALIZAÇÃO DO DIREITO PRIVADO"}

Primeiramente, mister fazermos uma breve análise acerca do chamado "constitucionalismo", movimento político de cunho eminentemente liberal que veio por

\footnotetext{
2 "La necesidad de interpretar el presente significa comparar el pasado, como proceso histórico, y también mirar hacia el futuro, como perspectiva de sociedad (no sólo como individuo)" (tradução livre). GHERSI, Carlos Alberto. "La Pobreza Jurídica y el Ejercicio de los Derechos Fundamentales: El valor de las liberdades negativas". Revista de Direito do Consumidor. Ano 11, n.43. São Paulo: Revista dos Tribunais, jul./set. 2002, p. 11.

${ }^{3}$ Segundo JESÚS BALLESTEROS, citando Arnold TOYNBEE, a pós-modernidade significa mais um estágio da história humana que, por sua vez, é resultado da própria liberdade humana, e não de leis naturais casuísticas como propugnam as teses deterministas; um estágio de resistência, e não de decadência: "Existe la posibilidad de la decadencia, pero existe también la posibilidad de la plenitud. La elección entre decadencia e plenitud está em función de la respuesta a los retos de la sociedad actual. La decadencia supondría la carencia de vibración ante tales problemas, mientras que la plenitud supone la creatividad, el afrontar tales retos com sentido de responsabilidad. Tal diferenciación es la que puede permitir distinguir entre modernismo o postmodemidad como decadencia y genuina postmodernidad como resistencia." (grifos do autor). BALLESTEROS, Jesús. Postmodernidad: decadencia o resistencia. 2 ed. Madrid: Tecnos, 2000, p. 101 e 102.
} 
ser a fonte primordial das questões relativas ao direito privado e ao direito constiucional. Como bem sustentado por AMARAL JUNIOR, "Constituição $e$ Codificação são institutos jurídicos típicos da cultura ocidental moderna" "4. Quer dizer, não há como conceber um estudo da codificação isolado do estudo do constitucionalismo (ou do surgimento das Constituições escritas e rígidas), ou viceversa; o próprio constitucionalismo foi uma espécie de codificação, na medida em que transportou valores políticos importantes na época para um documento escrito e pretensamente normativo (digo pretensamente pois como se verá adiante a Constituição só veio por ter "força normativa", efetivamente, na contemporaneidade ${ }^{5}$ ), sistemático e organizado mediante prescrições obrigatórias.

\section{A) O Constitucionalis mo Norte-Americano e Europeu: breves considerações} acerca da formação histórica do Estado Liberal e do Estado Social de Direito

O Constitucionalismo, em verdade, foi um movimento de cunho políticoideológico liberal que teve seu início pelos fins do século XVIII. Momento histórico de grande ebulição de idéias humanistas e iluministas, as quais, no campo político (principalmente francês) dirigiam-se como forma de oposição ao absolutismo monárquico ou aos autoritarismos de então. De fato, o constitucionalismo, calcado na doutrina da separação de poderes de Montesquieu (forte exemplo é o art.16 da Declaração de Direitos do Homem e do Cidadão, em que se demonstra que não é qualquer texto que constitui e representa uma verdadeira Constituição, para o constitucionalismo), ganhou força como uma tentativa liberal (porque fulcrada no princípio máximo da liberdade, garantida pela lei, bem como nas idéias de MONTESQUIEU) de contraposição ao Estado Burocrático Nacional Moderno, no qual havia uma concentração das funções de Estado em um só poder (o Monarca), ainda que

\footnotetext{
4 AMARAL JUNIOR, José Levi. "Constituição e Codificação: primórdios de um binômio". A Reconstrução do Direito Privado. Organização: Judith Martins-Costa. São Paulo: Revista dos Tribunais, 2002, p. 56.

${ }^{5}$ Ainda que se falasse desde HANS KELSEN em uma espécie de 'e ficácia normativa' da Constituição, sua plena caracterização como tal iniciou com os estudos de KONRAD HESSE, acerca das relações entre a Constituição juríd ica e a realidade político-social, bem como os limites e pressupostos de sua eficácia, eminentemente na sua obra A Força Normativa da Constituição. Tradução do original em alemão de Gilmar Ferreira Mendes. Porto Alegre: Sérgio Antônio Fabris Editor, 1991.
} 
na Inglaterra a função legislativa já tenha sido separada da figura do rei e depositada no Parlamento (com fundamento na doutrina de LOCKE) ${ }^{6}$.

Desta forma, surgiram as primeiras Constituições modernas, cuja única finalidade era estabelecer um programa político que limitasse o poder (internamente e externamente, essa pela soberania) e estabelecesse a organização fundamental do Estado, devendo consagrar, necessariamente, a divisão de poderes. Ainda, tal organização do Estado estava fundada precipuamente nos direitos fundamentais do cidadão (meramente direitos individuais), cujo valor maior era, sem dúvida, o da liberdade. Foi neste cenário que iniciou-se as primeiras elaborações dos códigos civis, destinados, pois, a regular as relações privadas da sociedade dentro deste ideário liberal ${ }^{7}$. Desta forma, era necessário, diante de uma Constituição suprema, escrita e rígida, fundada, como dissemos, nos direitos individuais e no valor da liberdade e legalidade, Códigos que se coadunassem com esse imaginário, razão pela qual foram elevados, em tais diplomas jurídicos, como superiores, a autonomia privada e a liberdade contratual ${ }^{8}$.

Assim, a relação entre o direito privado e o constitucional é muito antiga na história do direito, mas que ganhou relevância a partir do século XVIII/XIX pelos movimentos de codificação civil e constitucional ${ }^{9}$. A peculiaridade deste momento

\footnotetext{
${ }^{6}$ SOUZA JUNIOR, Cezar Saldanha. O Tribunal Constitucional como Poder. Uma nova teoria da Di visão de Poderes. São Paulo: Me mória Juríd ica Editora, 2002, p. 49 a 52; 55 a 63.

${ }^{7}$ O ideário liberal da Codificação manifesta o que NATALINO IRTI cunhou de "idade da segurança", nascida da estrutura social burguesa calcada no individualismo e na autonomia plena da vontade: "Il mondo della sicurezza é, dunque, il mondo dei codici, che traducono, in ordinate sequence di articoli, $i$ valori del liberalismo ottocentesco. Di qui il significato 'constituzionale' dei codici civili, nel senso che essi non si limitano a disciplinare semplici congegni tecnici (piú o meno perfetti e completi), ma raccolno e fissano la filosofia della rivoluzione borghese. (...) come la 'Dichiarazioni di diritti' garantiscono le libertá politiche dei singoli nei rapporti con lo Stato, i codici tutelano le 'libertá civili dell'individuo nella sua vita privata contro le indebite ingerenze del potere politico "' (grifamos). IRTI, Natalino. L'e tá della Decodificazione. 4 ed. Milano: Giuffré Editore, 1999, p. 23.

8 Nesse mesmo sentido, asseverou GUSTAVO TEPEDINO: "A codificação, como todos sabem, destinava-se a proteger uma certa ordem social, erguida sob a égide do individualismo e tendo como pilares nas relações privadas, a autonomia da vontade e a propriedade privada. O legislador não deveria interferir nos objetivos a serem alcançados pelo indivíduo, cingindo-se a garantir a estabilidade das regras do jogo, de tal maneira que a liberdade individual, expressão da inteligência de cada um dos contratantes, pudesse se desenvolver francamente, apropriando-se dos bens jurídicos, os quais, uma vez. adquiridos, não deveriam sofrer restrições ou limitações exógenas". TEPEDINO, Gustavo. "As relações de Consumo e a Nova Teoria Contratual". Temas de Direito Ci vil. 3 ed. Rio de Janeiro: Renovar, 2004, p. 220.

9 PONTES DE MIRANDA refere o caráter histórico das relações entre direito constitucional (público) e direito privado, delimitando o período liberal como marco da divisão entre as duas áreas: "Na Idade Média, a compenetração dos dois ramos do Direito foi notável. Serviço militar e contribuição supunham algo de convencionado, ou de unilateralmente aceito; certos direitos privados dependiam de direitos públicos, ligando-se a serviços militares e outras situações de ordem subordinativa. Foi a liberdade de contratar que veio arrebentar os laços políticos entre os que trabalham e os que empregam os
} 
histórico está na natureza da Constituição, entendida como um programa político supremo a guiar e fundamentar as leis, nada mais que isso. Não havia, pois, regra constitucional, em tais constituições, que se pudesse limitar de alguma forma o legislador, em fixar os conteúdos das regras civis: existiam apenas valores individuais e princípios que não poderiam ser violados, sob pena de inconstitucionalidade (tendentes a abolir, por exemplo, alguma liberdade prevista na Constituição) - contudo, não se pode dizer que tais disposições constitucionais tivessem alguma força normativa própria ${ }^{10}$, pois esta residia quase que totalmente na lei. Institutos como obrigações, direitos reais, família e sucessões, são definidos em lei, na forma e conteúdo, e devem respeitar os valores e princípios constitucionais. Se, por exemplo, o legislador optasse por limitar a propriedade, ou distribuí-la conforme interesses meramente políticos ou corporativos, tal medida não seria inconstitucional, pois cabe ao legislador tomar tais decisões, desde que não abolisse o direito próprio da propriedade, que, então, feriria a liberdade prevista na Constituição ${ }^{11}$.

Na Europa, ganha ênfase o exemplo francês, pelo famoso Código de Napoleão de 1801, o qual previa uma parte conceituale outra mais específica (tratamento jurídico dos institutos civis: obrigações, propriedade e família; ou seja, pessoas, bens, fatos). Dito Código consagra este estatuto civil como supremo na regulação das relações jurídicas privatísticas ${ }^{12}$, destinado a regulamentar, em todo o seu texto, quaisquer situações jurídicas presentes e futuras, sendo, posteriormente, criticado por ser

trablhadores". PONTES DE MIRANDA, Francisco Cavalcanti. Comentários à Constituição de 1967. Tomo I. São Paulo: Revista dos Tribunais, 1967, p.110 e 111.

${ }^{10}$ A esse respeito, mostrou HANS KELSEN o caráter mínimo de juridicidade e normatividade das Constituições resultantes do constitucionalismo, pontuando, especificamente, o período da passagem da Monarquia Absoluta para a Monarquia Constitucional: "Na monarquia absoluta, a distinção entre o grau da Constituição e o grau das leis é, decerto, teoricamente possível, mas não desempenha na prática nenhum papel, já que a Constituição consiste unicamente no princípio de que toda expressão da vontade do monarca é uma norma jurídica obrigatória. Não há, portanto, forma constitucional particular, isto é, normas jurídicas que submetem a regras diferentes a elaboração das leis e a reforma da Constituição; nela não tem sentido o problema da constitucionalidade das leis. A transição para a monarquia constitucional acarreta, precisamente a esse respeito, uma modificação decisiva, que se exprime de maneira assaz característica na expressão 'monarquia constitucional'. A maior importância que a noção de Constituiçãa adquire então, a existência de uma regra - regra que é precisamente a Constituição - segundo a qual as leis só devem ser feitas de certa forma, a saber, co m a colaboração da representação nacional..." (grifamos). KELSEN, Hans. "Jurisdição Constitucional". Jurisdição Constitucional. Tradução do original alemão de Alexandre Krug. São Paulo: Martins Fontes, 2003, p. 127 e 128.

${ }^{11}$ Essa é, pois, a razão jurídica pela qual os direitos sociais foram, posteriormente, colocados nas Constituições: qualquer tentativa de limitação das liberdades - mesmo que para favorecer alguma parte desfavorável no contrato, como o trabalhador - era considerada inconstitucional.

${ }^{12}$ É o que MIGUEL REALE refere como 'constituição do homem comum' em O Projeto do Novo Código Civil. São Paulo: Saraiva, 1999, p. 03. 
caracterizado como um "sistema fechado"13. Obviamente, a maneira como foi concebido o Código, como já fora dito antes, ajusta-se à mentalidade política da época, alinhada com a doutrina liberal prevalente desde então.

Contudo, verificou-se, a partir das mudanças sociais ocorridas na Europa (manifestadas principalmente pelas doutrinas socialistas desconformes com os abusos de uma elite econômica representante dos grandes industriais da Revolução Industrial), que a doutrina liberal então hegemônica já não mais era objeto de consenso na sociedade. Dita mudança social teve seus reflexos no Direito, na medida em que surgiram as primeiras críticas à Constituição de cunho liberal bem como ao Código Civil dotado de prescrições fechadas, muitas das quais colocavam a autonomia privada e liberdade contratual como institutos intocáveis e ilimitáveis.

No campo do direito constitucional, a crise deste período recaiu sobre a ausência na Constituição de disposições que garantissem direitos a todos, assim cunhados como direitos sociais; outrossim, estabeleceu-se uma crítica da fórmula Montesquiniana dos três poderes, separados e iguais, surgindo a necessidade de separação de mais uma função de estado, a função governamental, distinta da Chefia de Estado (posto que ambas, no modelo Montesquieu, encontravam-se concentradas no "Poder Executivo").

$\mathrm{Na}$ Europa, como salienta CEZAR SALDANHA ${ }^{14}$, ditas modificações constitucionais foram fruto da formação do Estado Social Contemporâneo, consagrado no século XX pela Constituição de Weimar (1919), a qual prevê direitos sociais que, da mesma forma que a Constituição do México de 1917, não eram previstos constitucionalmente. A razão pela qual houve a necessidade de serem colocados na Constituição supre uma questão técnica, qual seja, de que qualquer ato que fosse atentatório a alguma liberdade (prevista nas então Constituições liberais) - dirigido a proteger alguma demanda social, por exemplo - era julgado inconstitucional, posto que não era protegido pela mesma ordem constitucional.

A partir, pois, do Estado Social de Direito, podemos perceber um germe da força normativa da Constituição, já considerada como fundamento de validade do sistema jurídico, legitimando sua própria validade e supremacia. As próprias técnicas de

\footnotetext{
${ }^{13}$ Nessa linha, observa GUSTA VO TEPEDINO: "Todos os institutos do Direito Civil, a rigor, foram perdendo a estrutura abstrata e generalizante, em favor de disciplinas legislativas cada vez mais concretas e especificas". TEPEDINO, op. cit., p. 219. Quer dizer, nem todas as matérias de cunho privatístico necessariamente passaram a ser previstas em um código, mas especificadas em leg islações próprias, configurando o que NATALINO IRTI chamou de 'microssistemas', e que CLÁUDIA LIMA MARQUES refere como fontes jurídicas coexistentes (resumida no termo 'diálogo das fontes', que estudar-se-á mais adiante).

${ }^{14}$ SOUZA JUNIOR, O Tribunal Constitucional, p. 81.
} 
controle de constitucionalidade passam a aperfeiçoar-se, principalmente na Alemanha, vindo por, mais tarde, originar o Tribunal Constitucional ${ }^{15}$.

Porém, o Estado Social de Direito não evitou a experiência totalitária, vivida na Europa, e que marcou a história mundial até nossos dias. Muito dessa experiência deveu-se, exatamente, à natureza da Constituição, que, mesmo consagrando direitos sociais, permaneceu como um programa político, sem uma força normativa direta maior. A partir do fim da segunda guerra mundial, estando a Europa decidida a não mais viver o totalitarismo - principalmente a Alemanha - é que passou-se a propugnar a consagração de valores máximos da comunidade política, que privilegiassem a pessoa humana em si considerada, na medida de sua dignidade ${ }^{16}$. Por óbvio, dita mudança de pensamento no direito constitucional teve reflexos diretos no direito civil, mormente a partir da tutela, na Constituição, de institutos de direito civil até então assegurados apenas em lei, a qual tão largamente foi usada no período totalitário para fins ideológicos, inclusive contra o próprio direito civil.

O Brasil não ficou alheio às mudanças constitucionais européias. Já na Constituição de 1946 observa-se a preocupação em garantir os direitos-liberdades e alguns direitos sociais, bem como o retorno a um regime democrático, superando o período do Estado Novo e acompanhando o novo cenário mundial do pós-2 $2^{\text {a }}$ Guerra Mundial: "Na esteira do constitucionalismo europeu ocidental resultante do pós-2a Guerra, a Constituição voltou-se inteira ao modelo do Estado democrático e social de Direito" ${ }^{\text {17 }}$. Observa-se que, mesmo no período autoritário seguinte (1964-1984), não houve uma supressão constitucional à forma legis lativa de disposição dos conteúdos de direito ordinário, principalmente no que competia ao direito civil, posto que matérias

\footnotetext{
${ }^{15}$ Sobre o Tribunal Constitucional, e da necessidade de centralização do controle de constitucionalidade, excelente trabalho de FERRERES COMELLA, Victor. Las Consecuencias de centralizar el Control de Constitucionalidad de la ley en un Tribunal Es pecial. Algunas reflexiones acerca del activis mo judicial. Barcelona: Universidade Po mpeu Fabra, 2005.

${ }_{16}$ As afirmações de HESSE comprovam o espírito do período histórico mencionado: "A Constituição jurídica não significa simples pedaço de papel, tal como caracterizada por Lassalle. Ela não se afigura "impotente para dominar, efetivamente, a distribuição de poder" tal como ensinado por Georg Jellinek e como, hodiernamente, divulgado por um naturalismo e sociologismo que se pretende cético. A Constituição não está desvinculada da realidade histórica concreta do seu tempo. Todavia, ela não está condicionada, simplesmente, por essa realidade. Em caso de eventual conflito, a Constituição não deve ser considerada, necessariamente, a parte mais fraca. Ao contrário, existem pressupostos realizáveis (realizierbare Voraussetzungen) que, mesmo em caso de confronto, permitem assegurar a força normativa da Constituição". HESSE, A Força Normativa, p. 19.

${ }^{17}$ SOUZA JUNIOR, Cezar Saldanha. Constituições do Brasil. Porto Alegre: Sagra Luzzatto, 2002, p. 61. E continua o eminente professor: "As múltiplas disposições da carta de 1946 expõem claramente esse retorno à Democracia Social... ao lado de todo um conjunto de princípios de Justiça Social. Os direitos liberdades foram revigorados e declarou-se pela primeira vez no País que a lei não poderia excluir da apreciação do Judiciário qualquer lesão de direito individual" (grifamos; p. 61).
} 
específicas desta seara já encontravam-se dispostas no Código Civil então vigente (de 1916) e em leis esparsas ${ }^{18}$. Na Constituição de 1967 verificou-se a introdução da denominada 'lei complementar', e, mesmo a mais autoritária das Constituições - a de 1969 - manteve o processo legislativo, apesar de ter aumentado os poderes do Presidente da República na edição de decretos-leis ${ }^{19}$. Desta forma, é incontestável que existe, na tradição constitucional brasileira, uma busca de conservação da função da legislação como reguladora do direito ordinário, que não foi diferente com o advento da Constituição de 1988.

Efetivamente, foi a partir da Constituição de 1988 (muito devido à forma de seu texto e a expansão de seu conteúdo) em que se discutiu uma maior ingerência das normas constitucionais nas relações privadas, diante da natureza das regras postas no texto constitucional, o que ocasionou, inclusive, o aumento de demandas judiciais de aplicação direta de tais normas em casos concretos de natureza privada ${ }^{20}$. Quer dizer, o próprio direito civil brasileiro foi revisto sob a perspectiva da "Constituição Cidadã": a legislação infra-constitucional passou a acompanhar os valores constitucionais de $1988^{21}$, e o rompimento com a visão liberal do Código Civil de 1916 foi definitivo com a aprovação do "novo" 22 Código Civil em 2002.

${ }^{18}$ PONTES DE MIRANDA faz u ma rica análise da relação entre o direito constitucional e o ordinário dentro da tradição constitucional brasileira, chamando de 'direito dispositivo' e 'dire ito interpretativo' as regras de direito civil atinentes à autonomia da vontade: "O que fica ao 'ius dispositivum' e ao 'ius interpretativum', depois de se por de parte o 'ius cogens', é o que se denomina campo de 'autonomia': as partes podem dispor o que entendam; se dispuserem, obedecer-se-á ao que dispuserem, ou, no caso de dúvida, ao que se deve concluir, interpretativamente; se não dispuserem, nada se entenderá inserto no branco, volitivo, que deixaram, ou se observará o que o ius dispositivum, se o houver, ordene que se tenha por disposto. (...) Nas Constituições é preciso, sempre, mostrar-se a natureza da regra jurídica, para se saber se houve infração pela lei". (grifa mos). PONTES DE MIRANDA, Comentários, p. $122 \mathrm{e}$ 123.

19 Sobre a Constituição de 1969, observa o professor CEZAR SALDANHA: "Entretanto, sob sua vigência, somente uma vez veio a ser o Congresso posto em recesso... De resto - e aqui uma diferença importante entre a experiência da Constituição de 1969 e a da Constituição de 1937 - o Congresso sempre esteve em funcionamento e nunca deixaram de ser realizadas eleições parlamentares..." (grifamos). SOUZA JUNIOR, Constituições do Brasil, p. 76.

${ }^{20}$ Tais regras constitucionais - como as concernentes à família, à propriedade, à empresa, à ordem econômica, e inclusive às trabalhistas - levou a uma discussão entre os constitucionalistas acerca da aplicabilidade de tais normas, se feitas diretamente pelo juiz ou indiretamente, via leg islador. Sobre a aplicabilidade direta, vide trabalho de SA RLET, Ingo. "Direitos Fundamentais e Direito Privado: algu mas considerações em torno da vinculação dos particulares aos direitos fundamentais". Re vista de Direito do Consumidor. Ano 09, n. 36. São Paulo: Revista dos Tribunais, out./dez. 2000, p. 54-102. Sobre a aplicabilidade indireta, vide HECK, Luis Afonso. "Direitos Fundamentais e sua influência no Direito Civil". Re vista de Direito do Consumidor. n. 29. São Paulo: Revista dos Tribunais, jan./mar. 1999, p. 40-54. Sobre a necessidade de se estabelecer um campo para o direito constitucional e outro para o direito ordinário, e da competência do legislador, vide SOUZA JUNIOR, Cezar Saldanha. "Direito Constitucional, Direito Ordinário, Dire ito Judiciário". Cadernos do Programa de Pós-Graduação em Direito-PPGDir./UFRGS. N.03. Porto Alegre, mar. 2005, p. 07-18.

${ }^{21} \mathrm{Na}$ visão de MANOEL GONÇALVES FERREIRA FILHO, u ma gradual evolução social e política brasileira fez culminar no texto da Constituição de 1988, a qual introduziu, com mais clareza, a ordem 


\section{B) O "Constitucionalismo de Valores" do Pós-Segunda Guerra e a}

\section{“Constitucionalização" de institutos de Direito Civil: o exemplo ale mão}

Em oposição ao "constitucionalismo" liberal, o "constitucionalismo de valores", como a própria denominação já mostra, preconiza a existência necessária de, em qualquer Estado que seja Democrático de Direito, uma Constituição que garanta um mínimo de valores, fulcrados todos no princípio da dignidade da pessoa humana. Este constitucionalismo, como reação ao totalitarismo antecedente, e em paralelo à Declaração de Direitos Humanos de 1948, preconiza a proteção da dignidade existencial da pessoa humana - devendo todo o direito ser fundamentado neste princípio - , o reforço do compromisso da Constituição com os direitos fundamentais, principalmente com os direitos-liberdades (os quais limitam a ação do Estado), o fortalecimento da proteção dos direitos sociais e poíticos, a consagração do princípio democrático e do Estado de Direito, e o pluralismo ideológico e político ${ }^{23}$. Nesse sentido, protagonista foi a Lei Fundamental de Bonn de 1949, a qual prevê em seu texto todas essas disposições, tornando-se modelo do que os alemães chamam Verfassungsstaat, ou Estado Constitucional.

Com efeito, ao proteger explicitamente os direitos fundamentais em seu texto, a Lei Fundamental inaugura o que mais tarde se cunhou de "constitucionalização" do direito civil. Na verdade, a discussão entre os alemães, diante do texto constitucional, reside, até hoje, no grau de eficácia de tais normas jurídicas, tendo em vista que passouse a admitir (com fundamento na teoria kelseniana) uma força normativa da Constituição, diante da natureza das normas dispostas em seu corpo, obrigatórias e cogentes. O próprio aperfeiçoamento da técnica de controle de constitucionalidade leva a esta constatação, na medida em que a Constituição obriga todas as normas inferiores

econômica e social em suas disposições: “As Constituições modernas não são apenas políticas, como fazia questão de se dizer a Carta de 25 de março de 1824, a Constituição política do Império do Brasil. Propõe-se também a reger o 'econômico'e o 'social'. Apresentam-se, por isso, como constituições políticas, econômicas e sociais. (...) No Brasil, a primeira a adotá-lo foi a de 1934. Desta, um Título, o IV, foi dedicado à Ordem Econômica e Social, e outro, o V, á Família, Educação e Cultura. Em 1967, tal linha foi mantida, assim como na Emenda n. 1/69, havendo um título voltado, exatamente, para a Ordem Econômica e Social e outro para a Família, Educação e Cultura. Na Constituição de 1988, com mais lógica, se previu, por um lado, a Ordem Econômica e Financeira e, de outro, a Ordem Social, incluindo Seguridade Social, Educação, Cultura, Desporto, Família, etc.”. FERREIRA FILHO, Manoel Gonçalves. Estado de Direito e Constituição. 2 ed. São Pau lo: Saraiva, 1999, p. 86 e 87.

22 Entre aspas pois sabe-se que o Código Civil aprovado em 2002 é, em verdade, um projeto elaborado em 1975, ainda que com emendas atualizadoras em seu texto.

${ }^{23}$ SOUZA JUNIOR, O Tribunal Constitucional, p. 106 a 109. 
(e atos jurídicos) a serem conformes às suas disposições - obrigando, diretamente, o legislador.

Portanto, é no problema da eficácia de tais normas constitucionais - mormente, a chamada "eficácia contra terceiros" ou "efeito horizontal" (drittwirkung) que reside a questão atinente ao direito civil: os direitos fundamentais vinculam diretamente o particular? Se vinculam diretamente, como poderão regular os atos da vida civil, ou institutos como contratos, por exemplo? Essa discussão foi muito forte e intensa entre os constitucionalistas ${ }^{24}$, mas que de certa forma foi pacificada judicialmente a partir da "Sentença Lüth" emanada do Tribunal Constitucional Alemão. Nesta decisão, o Tribunal direcionou-se a optar pela eficácia mediata ou indireta, ou seja, intermediadas ou pelo legislador ou pelo judiciário, que deverá interpretar o caso conforme a Constituição. Quer dizer, os direitos fundamentais são linhas diretivas da decisão judicial ordinária, posto que não deverá o juiz pronunciar-se acerca da constitucionalidade ou não da situação em concreto, ou aplicar diretamente algum direito fundamental, sob pena de interferir na competência do Tribunal Constitucional para tanto, definida na própria Lei Fundamental ${ }^{25}$. O fundamento da decisão do Tribunal reside no conteúdo objetivo dos direitos fundamentais e seu efeito irradiador no direito civil, devendo ser os mesmos observados pelo juiz na decisão em concreto, podendo a parte, irresignando-se com a interpretação judicial, propor recurso constitucional.

Assim, em casos envolvendo relações entre particulares (um contrato, por exemplo), os direitos fundamentais exercem influência, mas, conforme o Tribunal Constitucional alemão, não obrigam ou vinculam diretamente o particular, mas sim o legislador, que tem a função primeira de regular as situações privadas de forma a resguardar tais direitos fundamentais. Os particulares vinculam-se à lei, mas podem irresignar-se contra ela ou contra uma conduta de outro particular (pessoa jurídica, também) caso entenda existir alguma violação constitucional. Ao fim e ao cabo, se presente um caso concreto, será resolvido pelo juiz ordinário.

LUIS AFONSO HECK explica-nos com clareza: “Um conflito entre privados sobre direitos e deveres de normas de conduta, jurídico-fundamentalmente influenciadas, do direito civil permanece, material e processualmente, um conflito jurídico civil" ${ }^{26}$. Quer dizer, a relação jurídica entre particulares não perde a sua

\footnotetext{
${ }^{24}$ Principalmente em autores como KONRAD HESSE, NEUNER, e CANARIS.

${ }^{25}$ HECK, op.cit., p. 44.

${ }^{26}$ Id., ib., p. 46.
} 
natureza civil, apenas submete-se, como qualquer outra relação jurídica, às disposições constitucionais, precipuamente os direitos fundamentais. E finaliza o autor: " $O$ conteúdo jurídico dos direitos fundamentais como normas objetivas desdobra-se no direito privado por meio de prescrições que dominam diretamente esse setor jurídico... interpretado e empregado é o direito civil,..." 27 , à luz da Constituição.

Desta forma, deve-se entender o que se chama por "constitucionalização": não se trata, propriamente, de ter a Constituição agregado disposições civis em seu texto, ou tentado regular o direito civil em superioridade às leis infra-constitucionais, numa tentativa de colocar o público sobre o privado, como afirmam alguns, mas sim na necessidade, diante da evolução histórico-política constitucional e jurídica, de assegurar, tutelar, consagrar institutos do direito civil no texto constitucional, a fim de evitar que o legislador, em incorrendo em arbitrariedade, venha a abolir ou modificar substancialmente o conteúdo do direito civil então existente. De igual maneira, trata-se de assegurar na Constituição direitos civis importantes e essenciais para a comunidade política, que, por opção dela mesma, não poderão ser alterados nem pelo legislador ordinário, nem pelo particular, nem pela Administração, nem pelo Governo.

\section{II - A “CONSTITUCIONALIZAÇÃO" DO DIREITO CIVIL NA CONTEMPORANEIDADE}

Levando em consideração a noção de "constitucionalização" do direito civil como uma proposta histórico-jurídico-política de consagrar, nas Constituições (advindas do constitucionalismo de valores), institutos civis fundamentais para a sociedade política, devendo fazer parte do texto constitucional, pode-se afirmar que a presença de um conteúdo civil "constitucional" não inaugura um direito civil constitucional, posto que não é esta a finalidade da Constituição ${ }^{28}$. Se assim o fosse, tal objetivo suprimiria inclusive a competência específica do juiz ordinário em analisar casos concretos envolvendo relações jurídicas privadas, o que causaria uma certa confusão no sistema de controle de constitucionalidade, segundo a doutrina alemã dantes vista, e seguida

\footnotetext{
${ }^{27}$ HECK, op.cit., p. 46, nota 25.

${ }^{28}$ Neste ponto, não concordamos com a posição de JOAQUÍN A RCE FLÓREZ - VALDÉS (El Derecho Civil Constitucional. Madrid: Editorial Civitas, 1991, p.173) quando refere existir um conjunto normativo formal de direito civil na Constituição; ora, isso é propugnar a existência de um sistema jurídico quase que paralelo ao constitucional (e não infraconstitucional, como é o correto), o que não é possível, logicamente, tendo em vista que a Constituição é u m todo, e esse todo constitui o fundamento de validade de todo o sistema normativo.
} 
entre nós por vários autores ${ }^{29}$, além de explicitar um fenômeno ao qual chamamos "totalitarismo constitucional", o que quer dizer, imbutir no Direito Constitucional todos os ramos do Direito, tornando o primeiro um "super-direito". A peculiaridade da Constituição reside na sua supremacia no sistema, posto que é fundamento de validade para as demais normas; mas não busca minar o campo próprio de atuação da lei civil ou administrativa.

\section{A) A relação dos direitos fundamentais constitucionais e os direitos civis: limites constitucionais ao direito privado}

Fruto do constitucionalismo dos valores, como já dito, a consagração nas Constituições dos direitos fundamentais é típico da pós-modernidade, eis que, até então, não se admitia nos diplomas constituciona is uma tábua de direitos e princípios tão rica e fulcrada na dignidade da pessoa humana ${ }^{30}$. Desta forma, tornou-se um desafio, para o direito do estado e também para o direito privado, esta harmonia entre os direitos previstos na Constituição e os demais direitos previstos em leis ou em atos jurídicos stricto sensu.

No Brasil, este reflexo dos direitos fundamentais no direito civil é ainda muito mais intenso que na Alemanha ou outros países europeus devido à natureza e à forma das descrições normativas constitucionais. Como já dito, observa-se na Constituição de 1988 uma presença significativa de normas de conteúdo civil, verbi gratia, os direitosliberdades do $\operatorname{art} .5^{\circ}$ (liberdade de associação, direito à herança, à intimidade, à informação, direitos autorais, direito do consumidor, propriedade industrial), fundamentais, portanto, impassíveis de objeto de reforma constitucional (art.60, $\S 4^{\circ}$, IV). Normas, pois, que asseguram a existência e essencialidade do direito civil no ordenamento jurídico, obrigando, inclusive, o legislador a regulamentar tais institutos em conformidade com a Constituição.

\footnotetext{
29 Nesse sentido, vide SOUZA JUNIOR, “Jurisdição Constitucional, Direito Ordinário, Direito Judiciário", 2005.

30 Sobre a relação entre os princípios e valores constitucionais, importante referir a lição de JORGE MIRANDA: “Os princípios ña se colocam, pois, além ou acima do Direito (ou do próprio Direito positivo); também eles - numa visão ampla, superadora de concepções positivistas, literalistas e absolutizantes das fontes legais - fazem parte do complexo ordenamental. (...) Se assim se afigura no geral, muito mais tem do ser no âmbito do Direito constitucional, tronco da ordem jurídica estadual, todo ele envolvido e penetrado pelos valores jurídicos fundamentais dominantes na comunidade; sobretudo, tem de ser assim na consideração da Constituição material como núcleo de princípios e não tanto de preceitos ou disposições articuladas" (grifamos). MIRANDA, Jorge. Manual de Direito Constitucional. Tomo II. Coimbra: Coimbra Editora, 1991, p. 224-225.
} 
Vê-se, portanto, que não veio a Constituição de 1988 regular o direito civil em lugar da legislação ordinária, ou tornar o direito civil constitucional, mas tão-somente dar segurança jurídica à própria existência de tais institutos (resguardando-os de eventual arbítrio do legislador), elevando-os a nível constitucional pela sua essencialidade em função da existência da pessoa humana, em sua dignidade. Ora, é necessário, para concretizar a dignidade da pessoa, a existência de sua liberdade; de um mínimo existencial, manifestado muitas vezes pela possibilidade de efetivação do consumo; da propriedade; da família; do fim da vida, já com idoso. Todos estes fatores são considerados pela Constituição como valores, devendo ser protegidos em seu texto, e efetivados ordinariamente pela lei e pela atividade judicial dos juízes.

Nessa mesma linha de raciocínio, importante referir o ensinamento do Ministro GILMAR FERREIRA MENDES: "Sem pressupor a existência das normas de direito privado relativas ao direito de propriedade, ao direito de propriedade intelectual e ao direito de sucessões, não haveria que se cogitar de uma efetiva garantia constiucional desses direitos...Fica evidente, pois, que a intervenção legislativa não apenas se afigura inevitável, como também necessária" "31 (grifamos). Quer dizer, a Constituição garante e delimita a proteção desses direitos, mas requer a intervenção legislativa para regulá-los, concretizá-los, completá-los ou até restringi-los (sem atingir o núcleo essencial do direito), o que demonstra a sua incapacidade de ser aplicada diretamente nas relações privadas e sociais, sem essa intermediação.

Aliás, cumpre efetuar breve análise a respeito da chamada eficácia imediata ou mediata dos direitos fundamentais sobre as relações privadas, ou que restou conhecido como 'eficácia horizontal' dos direitos fundamentais, mormente os de natureza civil ${ }^{32}$. A questão da diferenciação entre a aplicação dos direitos fundamentais numa relação jurídica particular-Estado - então relação 'vertical' - e numa relação entre particulares chamada 'horizontal' - foi desenvolvida principalmente entre os constitucionalistas alemães, como já dito, culminando com um pronunciamento relevante do Tribunal Constitucional alemão na conhecida 'Sentença Lüth'. A problemática residia, como refere ROBERT ALEXY, em duas vertentes: como ocorre dita vinculação dos

31 MENDES, Gilmar Ferreira, COELHO, Inocêncio Mártires, BRANCO, Paulo Gustavo Gonet. Hermenêutica Constitucional e Direitos Fundamentais. Brasília: Brasília Jurídica, 2002, p.214.

${ }^{32}$ To me-se, aqui, o termo 'eficácia', tendo em vista ser a estrutura jurídica então utilizada pelos principais autores alemães, ainda que alguns prefiram distinguir a 'validade' da 'eficácia' dos direitos fundamentais, como o faz CANARIS. A esse respeito, vide CANARIS, Claus-Wilhelm. "A influência dos direitos fundamentais sobre o direito privado na Alemanha" in Constituição, Direitos Fundamentais e Direito Privado. Tradução: Peter Naumann. Organização: Ingo Wolfgang Sarlet. Porto Alegre: Livraria do Advogado, 2003, p. 223-243. 
particulares aos direitos fundamentais, e em que medida, tendo em vista que trata-se de relação jurídica entre dois titulares de direitos fundamentais, ambos em situação de igualdade $^{33}$.

A fim de solucionar a problemática, surgiu entre os constitucionalistas duas propostas de análise acerca da influência dos direitos fundamentais na relação entre os particulares: a eficácia direta dos direitos fundamentais sobre tais relações jurídicas, e a eficácia imediata. A primeira trata o direito fundamental como uma norma jurídica que expressa valores aplicáveis a todo o ordenamento jurídico, a qual tem ingerência automática e direta sobre as relações jurídico-privadas, o que impede qualquer pretensão de limitação estipulada contratualmente, independentemente, inclusive, de previsão legal à respeito. Dito caráter normativo do direito fundamental ensejaria, adema is, um direito subjetivo do particular a algum tipo de indenização ou reparação, em caso de lesão ao direito fundamental ${ }^{34}$.

A segunda proposta - a qual consideramos ser a mais correta - considera os direitos fundamentais como integradores de uma ordem de valores objetiva (tal qual a teoria da eficácia imediata), mas que não possuem natureza normativa a ponto de serem diretamente e automaticamente aplicáveis nas relações entre particulares, sob pena de interferência abusiva sobre a autonomia privada e a liberdade contratual, gerando, ainda, uma estatização do direito privado, bem como um esvaziamento de seu conteúdo, presente precipuamente na lei e nos contratos e acordos celebrados ${ }^{35}$. Como já dissemos, a aplicação direta de prescrições constitucionais configura um verdadeiro totalitarismo constitucional, que não respeita os níveis essenciais do ordenamento jurídico, os quais preveêm para cada âmbito do direito a sua correta aplicação ${ }^{36}$.

\footnotetext{
33 ALEXY, Robert. Teoría de los Derechos Fundamentales. Madrid: Centro de Estudios Constitucionales, 1993 , p. 510 a 512.

34 SARLET, Ingo Wolfgang. "Direitos Fundamentais e Dire ito Privado: algumas considerações em torno da vinculação dos particulares aos direitos fundamentais". Revista de Direito do Consumidor. Ano 09, n. 36. São Paulo: Revista dos Tribunais, out./dez. 2000, p. 67 e 68.

35 “...os direitos fundamentais não são - segundo esta concepção-diretamente oponíveis, como direitos subjetivos, nas relações entre particulares, mas que carecem de uma intermediação, isto é, de uma transposição a ser efetuada precipuamente pelo legislador e, na ausência de normas legais privadas, pelos órgãos judiciais, por meio de uma interpretação conforme aos direitos fundamentais $e$, eventualmente, por meio de uma integração jurisprudencial de eventuais lacunas, cuidando-se, na verdade, de uma espécie de recepção dos direitos fundamentais pelo direito privado”. Id.,ib., p. 68 e 69.

${ }^{36}$ Sobre os níveis do ordenamento, explica o professor CEZAR SALDANHA: "A evolução politicojurídica do Ocidente chega ao século XXI reconhecendo uma estrutura funcional de ordenamento jurídico em que podemos divisar três níveis de direito positivo: $1^{\circ}$ ) o nível fundamental que, além de estabelecer o quadro da organização política básica do Estado, contempla os valores jurídicos superiores, boa parte deles formulados como direitos ditos fundamentais, o nível do direito constitucional; $2^{\circ}$ ) o nível intermediário onde está o direito ordinário, seja ele público ou privado, vale dizer, o conjunto de todas as normas gerais que, frente à realidade, procuram operacionalizar os valores
} 
Dessa forma, a 'eficácia irradiante' dos direitos fundamentais dar-se-á pelo legislador ordinário, pelos próprios particulares e pela interpretação das cláusulas gerais e conceitos indeterminados do direito privado em conformidade com a Constituição (como um todo, não só em relação aos direitos fundamentais). Acaso ocorra alguma ofensa à Constituição, esta deve ser analisada, judicialmente, mediante a interpretação jurídica (pelo juiz ordinário) ou, conforme o caso, por meio do controle de constitucionalidade (exclusivamente pelo Tribunal Constitucional).

\section{B) O Direito Privado na Constituição: desafios na pós-modernidade}

A expressão "pós-modernidade" é utilizada por ERIK JAIME para demonstrar a circunstância de mudança, ou de crise, ou de variabilidade do momento histórico em que vivemos e, portanto, do próprio Direito, por certo tendo bases sociológicas e filosóficas (de mudanças de pensamento) muito fortes ${ }^{37}$. Assim, sendo o direito fruto da sociedade, certamente sofrerá impactos constantes das mudanças sociais, e, em nosso tempo, não fica alheio às circunstâncias surgidas com a globalização e com a era "pósindustrial”. Para ERIK JAIME, vive-se uma crise de mudança, a qual implementa ao direito civil um grande desafio, no sentido de acompanhar tais modificações e superar dita crise. Desta maneira, JAIME apresenta uma proposta dita 'reconstrutora', baseada na identidade cultural da pessoa humana ${ }^{38}$ - tomada como indivíduo - e no

\footnotetext{
e os direitos fundamentais essenciais ao convívio interpessoal; e $3^{\circ}$ ) o nível concreto, o direito realizado, nos fatos da vida, pelos administradores e pelos juízes, cujo segmento mais importante poderíamos denominar de direito judiciário." (grifos do autor). SOUZA JUNIOR, "Direito Constitucional, Dire ito Ordinário, Dire ito Judiciário", p. 10 e 11.

${ }^{37}$ O pensamento de ERIK JAIME foi assim sintetizado por CLÁUDIA LIMA MARQUES: "A Tese de Jayme voltou-se inicialmente para os reflexos da pós-modernidade no direito internacional privado como ramo mais sensível aos contatos humanos internacionais de nosso tempo e as mudanças nos valores e modelos da sociedade. Mas a hipótese de trabalho de Jayme, qual seja de que o direito, como expressão cultural de um povo, sofre reflexos maiores ou menores das mudanças valorativas, econômicas, históricas, éticas e mesmo religiosas de seu tempo, é válida também para outros ramos do direito. Assim, em um tempo conhecido como pós-industrial, com uma filosofia pós-estruturalista e discursiva, uma era do vazio e do caos, de desregulamentação, de privatizações, de forte exclusão social, da 'euforia do individualismo e do mercado', era de globalização, de radicalismo tribal, de convivência e intolerância, de antinomias tão fortes que já se prevê o fim da história, a morte da ciência, o fim dos valores e outras catastróficas previsões para a nova era, em resumo, em uma época de crise pós-moderna, também o direito como ciência próxima da realidade social e voltada para sociedade estaria em crise e deve evoluir. Uma crise de mudança, uma crise de crescimento" (MARQUES, Cláudia Lima. "Laudatio para Erik Jaime - Memórias e Utopia". Cadernos do Programa de Pós-Graduação em Direito PPGDir./UFRGS. Vol. I, Número I, Março/2003. $3^{\text {a }}$ Tiragem, $2^{\text {a }}$ Edição. Porto Alegre: Universidade Federal do Rio Grande do Sul, dezembro de 2004, p. 57/58).

38 Afirma ERIK JAIME: "Podemos, portanto, constatar que ao desenvolvimento das sociedades multiculturais corresponde o reconhecimento, por parte do ordenamento jurídico internacional, da identidade cultural da pessoa como valor jurídico" (JAIME, Erik. "Sociedade Multicultural e Novos
} 
fortalecimento dos valores atinentes a essa mesma natureza humana. Na visão desse autor, as características da cultura pós-moderna no direito seriam o Pluralismo (o 'direito de ser diferente'), a Comunicação, a Narração, o retorno aos sentimentos, e a valorização dos direitos humanos ${ }^{39}$. Portanto, segundo ERIK JAIME, o direito terá que superar as mudanças e as crises a partir de uma solução sistemática mais fluída, mas flexível, pela passagem da superação dos paradigmas para a convivência dos paradigmas.

Essa convivência dos paradigmas, pois, é transportada para o direito na visão da convivência das diversas fontes jurídicas, ou mais especificamente, legislativas, traduzidas pela proposta do 'diálogo das fontes'. Assim, nessa linha exposta por ERIK JAIME $^{40}$, no direito privado, a existência de um sistema jurídico flexível, mutável, plural, constituído por várias fontes do direito, só poderá dar uma solução sistemática pós-moderna a partir da coordenação de todas as fontes legislativas. Este diálogo permite uma aplicação simultânea, coerente e equilibrada, posto que há, entre as fontes, influências recíprocas, que não poderão ser resolvidas meramente pelo sistema "moderno" de revogação. Claro está, contudo, que dita solução sistemática reside precipuamente no campo da hermenêutica ou interpretação jurídica, exigindo dos

Des envolvimentos no Direito Internacional Privado". Tradução do original em italiano por Cláudia Lima Marques e Julia Barros Schirmer. Cadernos do Programa de Pós-Graduação em Direito PPGDir./UFRGS. Vol. I, Número I, Março/2003. $3^{\mathrm{a}}$ Tiragem, 2a Edição. Porto Alegre: Universidade Federal do Rio Grande do Sul, de ze mbro de 2004, p. 96).

39 Ao explicar a escolha desses valores como os caracterizadores da cultura pós -moderna, ERIK JAIME admite exis tir u ma certa arbitrariedade na sua proposta, bem co mo não deixa c laro os exatos critérios para a seleção des ses valores, e não outros: "O ponto de encontro entre a cultura pós-moderna e o direito são os valores que têm em comum. ... O primeiro deles é o pluralismo (Pluralismus). Não apenas o pluralismo de formas, mas também de estilos. É também de estilos de vida, é a idéia de autonomia em escolher seu próprio modo de vida. O mundo pós-moderno é caracterizado por um 'direito à diferença'... O segundo valor: o mundo pós-moderno é caracterizado pela comunicação (Kommunikation) e por não ter mais fronteiras. De outra parte, não são apenas os meios técnológicos que permtitem a troca rápida de informação e imagens, mas também a vontade (Wille) e o desejo (Wunsch) de se comunicar dessas pessoas. Esse desejo emerge como valor comum. A terceira característica é a 'narração' (Narration): comunicar é também descrever, contar, narrar, observe-se já o alto nível da arte figurativa. O quarto valor é o retorno aos sentimentos...Podemos, porém, considerá-lo em relação à identidade cultural que pode conduzir a conflitos culturais, baseados em um sentimento forte de defesa de sua própria identidade cultural, de sua religião e de todas as outras expressões do individualismo. A escolha desses quatro valores da cultura pós-moderna...pode parecer arbitrária, mas essa escolha permite pôr em evidência a ligação entre direito e a cultura pós-moderna" (grifamos; JAIME, Erik. "Direito Internacional Privado e Cultura Pós-Moderna". Tradução de Lisiane Feiten Wingert, revisão de Cláudia Lima Marques. Cadernos do Programa de Pós-Graduação em Direito - PPGDir./UFRGS. Vol. I, Nú mero I, Março/2003. $3^{\mathrm{a}}$ Tiragem, $2^{\mathrm{a}}$ Edição. Porto Alegre: Universidade Federal do Rio Grande do Sul, de ze mbro de 2004, p. 106/107).

${ }^{40}$ MARQUES, Cláudia Lima. "Diálogo entre o Código de De fesa do Consumidor e o Novo Código Civil: Do 'Diálogo das Fontes' no combate às cláusulas abusivas". Revista de Direito do Consumidor. Ano 12, n. 45. São Paulo: Revista dos Tribunais, jan./mar. 2003, p. 74 e 75. 
juristas uma correta aplicação de tais fontes legislativas ao caso concreto e em conformidade com a Constituição.

Dessa maneira, o 'diálogo das fontes' no direito privado somente é possível, tomado como parâmetro de interpretação pelo jurista, se em conformidade com a Constituição. O interpréte - no caso, o juiz, que decide o caso concreto envolvendo uma relação jurídica de natureza civil - tem um compromisso em decidir da maneira mais justa possível, levando em conta as circunstâncias do caso concreto, sempre, todavia, conformando sua interpretação às normas constitucionais. Desta forma, o juiz que aplica simultaneamente, por exemplo, o Código de Defesa do Consumidor, o Código Civil e as leis do Sistema Financeiro de Habitação num caso concreto, deve fazê-lo de forma a não ferir qualquer prescrição constitucional, principalmente no que tange aos direitos fundamentais. Nesse sentido, mesmo um sistema jurídico flexível deverá estar submetido à Constituição, pois está dá o fundamento de validade ao próprio sistema, que não poderá ser contrário, logicamente, a mesma, sob pena de incorrer em insolucionável contradição.

Em uma outra perspectiva, a pós-modernidade, na proposta de JESÚS BALLESTEROS, não deve ser percebida, na história humana, tão-somente aos olhos da ciência natural, ou das ciências humanas, ou, até, das mudanças sociais na política e econômica, posto que ainda identificaríamos, nestas searas, elementos da então Modernidade. A pós-modernidade, como tal - expressão que, segundo BALLESTEROS, aparece na historiografia pela primeira vez na obra de TOYNBEE, $A$ Study of History, publicada entre 1934 e 1954 - pode ser identificada por determinados acontecimentos históricos que marcaram uma mudança forte de pensamento, quais sejam: 1) o final da Segunda Guerra Mundial, e o apelo pela paz, caracterizando o caminho da sobrevivência; 2) o processo de 'descolonização', marcado pelo respeito às culturas dirigido a um pensar 'ecumênico', definindo o caminho da pluralidade de culturas; 3 ) a conservação dos recursos naturais, despertando o pensar 'ecológico', no caminho da preservação ambiental local e global; 4) a importância dos valores femininos, resultando no caminho do desapego e da revalorização do cuidado.

Podemos afirmar, pois, na esteira do pensamento de BALLESTEROS, que a pós-modernidade, com todos os seus elementos, está centrada neste 'pensar ecumênico', no esforço de superação de um etnocentrismo ${ }^{41}$ (típico da Modernidade) para o

\footnotetext{
${ }^{41} \mathrm{O}$ etnocentrismo é uma expressão utilizada na Ciência Sociológica para referir-se à análise de uma outra realidade a partir dos olhos individuais e próprios da realidade do observador, que, por ter esse olhar
} 
reconhecimento do outro. E este reconhecimento parte do pressuposto de ver no outro o seu semelhante, independentemente de sua cultura e suas diferenças. Essa semelhança reside exatamente numa igual natureza humana, perfectibilizada na sua dignidade como humano, resultando numa visão uniformizadora e objetiva dos valores humanos a ser respeitados e perseguidos por todas as pessoas - valores esses que trascendem a identid ade cultural do indivíd uo.

É exatamente neste ponto que o direito assume o papel central de dirigir a vida humana para a consecução de tais valores. Muito mais importância, nesse sentido, temo direito constitucional (como garantidor dos princípios constitucionais cujo fundamento encontram-se na dignidade da pessoa humana) e o direito privado (como regulador das condutas humanas em respeito aos mesmos princípios e valores constitucionais), constituindo as duas áreas centrais do direito para a superação da crise pós-moderna, evidente aos nossos olhos, hoje. Para tanto, necessário será um perfeito diálogo entre o público e o privado, respeitando suas particularidades e ao mesmo tempo perseguindo, como diz BALLESTEROS, a 'pós-modernidade como resistência', sendo necessário 'relativizar o relativismo', encontrando uma comum resistência contra as violações à humanidade em quaisquer circunstâncias.

\section{CONSIDERAÇÕES FINAIS}

Entendemos, pois, ser imprescindível o equilíbrio entre o direito privado e o constitucional a partir da exata delimitação de suas áreas de atuação e competência. Quer dizer, não basta afastarmos o direito privado, e aplicarmos diretamente sobre casos concretos os direitos ou prescrições constitucionais, pois incidiríamos num verdadeiro totalitarismo constitucional, assim como num extremo relativismo jurídico, na medida em que dita aplicação dependerá sempre do aplicador - que pode interpretar a Constituição de uma forma, e outro aplicador de outra. Tampouco é razoável aplicar exclusivamente princípios e regras do direito privado, sem observar o ordenamento superior constutucional, que lhe confere fundamento e validade. É preciso uma visão de conjunto, aliada a um olhar específico sobre cada campo próprio do direito, sendo o

exclusivo, não identifica elementos que são próprios do fenômeno estudado, chegando a equívocos principalmente no que tange ao estudo da cultura do outro (muitas vezes caracterizando uma tentativa de superação de uma persepctiva sobre a outra). 
privado seara típica do direito ordinário e o constitucional (o público) próprio de uma jurisdição e legislação específica ${ }^{42}$.

Dessa forma, consideramos que o fulcro do problema das relações entre o direito civil e a Constituição estão, em verdade, na interpretação jurídica, bem como na exata delimitação dos campos jurídicos do direito ordinário e constitucional, que não deixaram de ter sua autonomia com os valores constitucionais nem com a eficácia normativa da Constituição. A palavra, pois, que ora propugnamos é "harmonia", ou "diálogo", e não "sobreposição" de um campo em outro. Oportuno salientar que a Constituição, ao apenas garantir os institutos civis, não toliu ao intérprete sua liberdade de análise do caso concreto e aplicação de fontes no mesmo caso. Apenas direcionou o intérprete a respeitar as disposições constitucionais, incontestavelmente superiores no sistema, mas perfeitamente harmoniosas como mesmo.

\section{REFERÊNCIAS BIBLIOGRÁFICAS}

AMARAL JUNIOR, José Levi. "Constituição e Codificação: primórdios de um binômio". A Reconstrução do Direito Privado. Organização: Judith Martins-Costa. São Paulo: Revista dos Tribunais, 2002, p. 54-70.

ALEXY, Robert. Teoría de los Derechos Fundamentales. Madrid: Centro de Estudios Constitucionales, 1993.

BALLESTEROS, Jesús. Postmodernidad: decadencia o resistencia. 2 ed. Madrid: Tecnos, 2000.

BARZOTTO, Luis Fernando. A Democracia na Constituição. Porto Alegre: Unisinos, 2003.

CANARIS, Claus-Wilhelm. "A influência dos direitos fundamentais sobre o direito privado na Alemanha". Constituição, Direitos Fundamentais e Direito Privado. Tradução: Peter Naumann. Organização: Ingo Wolfgang Sarlet. Porto Alegre: Livraria do Advogado, 2003, p. 223-243.

\footnotetext{
${ }^{42}$ Co mo refere HESSE: "La consequencia es que los jueces del orden civil argumentan ampliamente em sus fundamentos con los derechos fundamentales, y que además se refuerza la tendencia a dejar fluir los derechos fundamentales en el Derecho Privado también allí donde éste en modo alguno depende de ellos. El Tribunal Constitucional cae así en el peligro de convertirse en el supremo tribunal de los conflictos jurídico-civiles y de asumir de este modo un papel que la Ley Fundamental no le ha conferido....Al legislador del Derecho Privado corresponde constitucionalmente la tarea de transformar el contenido de los derechos fundamentales, de modo diferenciado y concreto, en Derecho inmediatamente vinculante para los participantes en uma relación jurídico-privada”. (grifo nosso em negrito; sublinhado, do autor). HESSE, Konrad. Derecho Constitucional y Derecho Privado. Tradução do original alemão para o espanhol de Ignacio Gutierrez Gutierrez. Madrid: Editorial Civitas, 1995, p.61 a 64.
} 
FACCHINI NETO, Eugênio. "Reflexões histórico-evolutivas sobre a constitucionalização do direito privado". Constituição, Direitos Fundamentais e Direito Privado. Organização: Ingo Wolfgang Sarlet. Porto Alegre: Livraria do Advogado, 2003, p. 11-56.

FERRERES COMELLA, Victor. Las Consecuencias de centralizar el Control de Constitucionalidad de la ley en un Tribunal Especial. Algunas reflexiones acerca del activismo judicial. Barcelona: Universid ade Pompeu Fabra, 2005

FLÓRES-VALDÉS, Joaquín Arce y. El Derecho Civil Constitucional. Madrid: Editorial Civitas, 1991.

FERREIRA FILHO, Manoel Gonçalves. Estado de Direito e Constituição. São Paulo: Saraiva, 1999.

GHERSI, Carlos Alberto. "La Pobreza Jurídica y el ejercicio de los Derechos Fundamentales. El valor de las liberdades negativas" in Revista de Direito do Cons umidor. Ano 11, n. 43. São Paulo: Revista dos Tribunais, jul./set. 2002, p. 11-20.

"Globalización y Derecho de Daños. Los Derechos constitucionales incumplidos" in Revista de Direito do Consumidor. Ano 12, n.47. São Paulo: Revista dos Tribunais, jul./set. 2003, p.09-18.

HECK, Luis Afonso. O Tribunal Constitucional Federal e o Desenvolvimento dos Princípios Constitucionais. Contributo para uma compreensão da Jurisdição Constitucional Fede ral Ale mã. Porto Alegre: Sergio Antonio Fabris Editor, 2005.

"Direitos Fundamentais e sua influência no Direito Civil" in Revista de Direito do Consumidor. n. 29. São Paulo: Revista dos Tribunais, jan./mar. 1999, p. 4054.

HESSE, Konrad. Derecho Constitucional y Derecho Privado. Tradução do original alemão para o espanhol de Ignacio Gutierrez Gutierrez. Madrid: Editorial Civitas, 1995.

IRTI, Natalino. L'etá della Decodificazione. 4 ed. Milano: Giuffré Editore, 1999.

JAIME, Erik. "Direito Internacional Privado e Cultura Pós-Moderna". Tradução de Lisiane Feiten Wingert, revisão de Cláudia Lima Marques. Cadernos do Programa de Pós-Graduação em Direito - PPGDir./UFRGS. Vol. I, Número I, Março/2003. $3^{\text {a }}$ Tiragem, $2^{\text {a }}$ Edição. Porto Alegre: Universidade Federal do Rio Grande do Sul, dezembro de 2004.

"Sociedade Multicultural e Novos Desenvolvimentos no Direito Internacional Privado". Tradução do original em italiano por Cláudia Lima Marques e Julia Barros Schirmer. Cadernos do Programa de Pós-Graduação em Direito PPGDir./UFRGS. Vol. I, Número I, Março/2003. $3^{\mathrm{a}}$ Tiragem, $2^{\mathrm{a}}$ Edição. Porto Alegre: Universidade Federal do Rio Grande do Sul, dezembro de 2004. 
KELSEN, Hans. "Jurisdição Constitucional". Jurisdição Constitucional. Tradução do original alemão de Alexandre Krug. São Paulo: Martins Fontes, 2003.

LUDWIG, Marcos de Campos. "Direito Público e Direito Privado: A superação da dicotomia". A Reconstrução do Direito Privado. Organização: Judith Martins-Costa. São Paulo: Revista dos Tribunais, 2002, p. 87-114.

MARQUES, Cláudia Lima. "Diálogo entre o Código de Defesa do Consumidor e o Novo Código Civil: Do 'Diálogo das Fontes' no combate às cláusulas abusivas". Revista de Direito do Cons umidor. Ano 12, n. 45. São Paulo: Revista dos Tribunais, jan./mar. 2003, p. 71-99.

"Laudatio para Erik Jaime - Memórias e Utopia". Cadernos do

Programa de Pós-Graduação em Direito - PPGDir./UFRGS. Vol. I, Número I, Março/2003. $3^{\text {a }}$ Tiragem, $2^{a}$ Ed ição. Porto Alegre: Universidade Federal do Rio Grande do Sul, dezembro de 2004.

. 'Igualdade entre Filhos no Direito Brasileiro atual - Direito pósmoderno?". Revista da Faculdade de Direito da UFRGS. Vol.16. Porto Alegre: Síntese, 1999, p. 21-40.

MENDES, Gilmar Ferreira, COELHO, Inocêncio Mártires, BRANCO, Paulo Gustavo Gonet. Hermenêutica Constitucional e Direitos Fundamentais. Brasília: Brasília Jurídica, 2002.

MIRAGEM, Bruno Nunes Barbosa. "O Direito do Consumidor como Direito Fundamental - Conseqüências jurídicas de um conceito". Revista de Direito do Cons umidor. Ano 11, n.43. São Paulo: Revista dos Tribunais, jul./set. 2002, p. 111132.

"Diretrizes interpretativas da função social do contrato". Revista de

Direito do Consumidor. Ano 14, n.56. São Paulo: Revista dos Tribunais, out./dez. 2005, p. 22-45.

MIRANDA, Jorge. Manual de Direito Constitucional. Tomo II. Coimbra: Coimbra Editora, 1991.

MURILLO, Maria Luisa. "The Evolution of Codification in the Civil Law Legal Systems: towards Decodification and Recodification". Transnational Law e Policy Journal. Vol.11:1. Houston Law Center University, 2001.

NEUNER, Jörg. "O Código Civil da Alemanha e a Lei Fundamental". Constituição, Direitos Fundamentais e Direito Privado. Tradução: Peter Naumann. Organização: Ingo Wolfgang Sarlet. Porto Alegre: Livraria do Advogado, 2003, p. 245-269.

PONTES DE MIRANDA, Francisco Cavalcanti. Comentários à Constituição de 1967. Tomo I. São Paulo: Revista dos Tribunais, 1967.

REALE, Miguel. O Projeto do Novo Código Civil. São Paulo: Saraiva, 1999. 
SARLET, Ingo Wolfgang. "Direitos Fundamentais e Direito Privado: algumas considerações em torno da vinculação dos particulares aos direitos fundamentais". Revista de Direito do Cons umidor. Ano 09, n. 36. São Paulo: Revista dos Tribunais, out./dez. 2000, p. 54-102.

SOUZA JUNIOR, Cezar Saldanha. O Tribunal Constitucional como Poder. Uma nova teoria da divisão de poderes. São Paulo: Memória Jurídica Editora, 2002.

"Direito Constitucional, Direito Ordinário, Direito Judiciário". Cadernos do Programa de Pós-Graduação em Direito-PPGDir./UFRGS. n. 03. Porto Alegre, mar. 2005, p. 07-18.

A Supremacia do Direito no Estado Democrático e seus Modelos Básicos. Porto Alegre: Novembro de 2002.

Constituições do Brasil. Porto Alegre: Sagra Luzzatto, 2002.

TEPEDINO, Gustavo. "As relações de Consumo e a Nova Teoria Contratual". Temas de Direito Civil. 3 ed. Rio de Janeiro: Renovar, 2004.

VIGO, Rodolfo Luis. Interpretação Jurídica. Tradução de Susana Elena Dalle Mura e Alfredo de J. Flores. São Paulo: Revista dos Tribunais, 2005. 